Article

\title{
Assessing the Performance of UAS-Compatible Multispectral and Hyperspectral Sensors for Soil Organic Carbon Prediction
}

\author{
Giacomo Crucil ${ }^{1, * \mathbb{C}}$, Fabio Castaldi ${ }^{1}$, Emilien Aldana-Jague ${ }^{1}$, Bas van Wesemael ${ }^{1}{ }^{\mathbb{D}}$, \\ Andy Macdonald ${ }^{2}(1)$ and Kristof Van Oost ${ }^{1}$ \\ 1 TECLIM, George Lemaitre Center for Earth and Climate, Earth and Life Institute, Universite Catholique de \\ Louvain, 1348 Louvain-La-Neuve, Belgium; fabio.castaldi@uclouvain.be (F.C.); \\ emilien.aldanajague@gmail.com (E.A.-J.); bas.vanwesemael@uclouvain.be (B.v.W.); \\ kristof.vanoost@uclouvain.be (K.V.O.) \\ 2 Sustainable Agriculture Sciences Department, Rothamsted Research, Harpenden, Herts AL5 2JQ, UK; \\ andy.macdonald@rothamsted.ac.uk \\ * Correspondence: giacomo.crucil@uclouvain.be
}

Received: 20 February 2019; Accepted: 25 March 2019; Published: 29 March 2019

check for updates

\begin{abstract}
Laboratory spectroscopy has proved its reliability for estimating soil organic carbon (SOC) by exploiting the relationship between electromagnetic radiation and key spectral features of organic carbon located in the VIS-NIR-SWIR $(350-2500 \mathrm{~nm})$ region. While this approach provides SOC estimates at specific sampling points, geo-statistical or interpolation techniques are required to infer continuous spatial information. UAS-based proximal or remote sensing has the potential to provide detailed and spatially explicit spectral sampling of the topsoil at the field or even watershed scale. However, the factors affecting the quality of spectral acquisition under outdoor conditions need to be considered. In this study, we investigate the capabilities of two portable hyperspectral sensors (STS-VIS and STS-NIR), and two small-form multispectral cameras with narrow bands in the VIS-NIR region (Parrot Sequoia and Mini-MCA6), to predict SOC content. We collected spectral data under both controlled laboratory and outdoor conditions, with the latter being affected by variable illumination and atmospheric conditions and sensor-sample distance. We also analysed the transferability of the prediction models between different measurement setups by aligning spectra acquired under different conditions (laboratory and outdoor) or by different instruments. Our results indicate that UAS-compatible small-form sensors can be used to reliably estimate SOC. The results show that: (i) the best performance for SOC estimation under outdoor conditions was obtained using the VIS-NIR range, while the addition of the SWIR region decreased the prediction accuracy; (ii) prediction models using only the narrow bands of multispectral cameras gave similar or better performances than those using continuous spectra from the STS hyperspectral sensors; and (iii) when used in outdoor conditions, the micro hyperspectral sensors substantially benefitted from a laboratory model calibration followed by a spectral transfer using an internal soil standard. Based on this analysis, we recommend VIS-NIR portable instruments for estimating spatially distributed SOC data. The integration of these sensors in UAS-mapping devices could represent a cost-effective solution for soil research and precision farming applications when high resolution data are required.
\end{abstract}

Keywords: soil organic carbon; proximal sensing; hyperspectral sensors; multispectral sensors; precision agriculture 


\section{Introduction}

Laboratory spectroscopy has proved its reliability for estimating the soil organic carbon (SOC) concentration by exploiting the relationship between electromagnetic radiation and organic carbon spectral features [1]. The key spectral regions affected by SOC content are located in the visible (VIS) region around $664 \mathrm{~nm}$ and in the SWIR region from 2100 to $2300 \mathrm{~nm}$ [2-4]. The accuracy of laboratory spectroscopy is mainly controlled by the technical characteristics of the spectrophotometers: (i) high spectral resolution, (ii) wide spectral range, (iii) stability of the measurement conditions, and (iv) low signal-to-noise ratio (SNR). Laboratory spectroscopy has now become a routine method to estimate SOC and other soil parameters. Although it results in robust and accurate estimates of soil properties, laboratory-based spectroscopy only provides an estimate at the sample point location and geostatistical techniques have to be used to infer continuous spatial information. The use of proximal [5] or remote sensing [6-8] could be very useful to provide more information on soil spatial variability at the field or even regional scale. In particular, satellite data are very attractive because of the large spatial coverage and short revisit time, which results in the availability of a larger number of images over the same area. The use of remote sensing data for SOC estimation, despite some promising results obtained with Sentinel-2 multispectral broad-bands [9], is currently hampered by the lack of suitable hyperspectral sensors mounted on the satellite platforms $[8,10,11]$. Within a few years, six satellites equipped with hyperspectral sensors will be launched $[12,13]$ and the future hyperspectral imagers could provide more reliable data for soil spectroscopy applications. However, the issue related to the low spatial resolution of remote data remains unresolved: most of the current and new satellite sensors have a spatial resolution (10-30 m) that could not allow a sufficient explanation of the short-range variability that characterizes some soil variables, especially if the objective is soil mapping for precision farming. Moreover, fixed revisit times are not optimal for an appropriate temporal coverage, due to the influence of cloud cover, or when dry and bare soil conditions are required. While the spatial resolution of airborne sensors is higher $(2-5 \mathrm{~m})$, the high operational costs do not generally allow multi-temporal data to be obtained, which are often necessary to increase the likelihood of collecting remote sensing soil data in an optimal condition, i.e., bare, without harvest residues, low roughness, and low soil moisture [14].

The recent development of Unmanned Aircraft Systems (UAS) [15,16] and lightweight spectrophotometers [17] has allowed the assessment of the spatial and temporal variability of soil properties at a high resolution $(<1 \mathrm{~m})$ and at relatively low costs. The advantages in terms of cost, flexibility, and spatial/temporal resolution, compared to aerial and satellite surveys, have been discussed in detail [18,19]. The new generation of hyper-/multi-spectral sensors that have become available during the last few years provides new opportunities for soil science and mapping [20]; UAS-based sensing may provide a very attractive solution for research, particularly where high-resolution spatial data is needed [17].

The technological push toward smaller sensors with a better performance is mainly implemented for precision farming applications with a strong focus on crop performance [4,21,22]. At present, the use of UAS-based applications in soil science is still in an early stage. To our knowledge, only a few authors have dealt with UAS-based multispectral imaging for soil property estimation (e.g., [17,21,23]), and we are not aware of any applications of hyperspectral UAS systems for predicting soil properties.

Most authors that deal with remote or UAS data directly calibrate the sensor signal of a limited number of pixels, i.e., they collect soil samples within bare fields, measure the soil property in the laboratory, and calibrate a multivariate model linking the measured soil property to the spectra extracted from the pixel at its sampling point [24]. Wider applicable estimation models could be calibrated by exploiting existing national or continental or soil spectral libraries [25,26]. Recently, Castaldi et al. [27] used the pan European LUCAS topsoil database [25] to estimate SOC content without applying spectral transfer between the calibration and validation dataset, because both sets of spectra were acquired using the same instrument (FOSS XDS Rapid Content Analyzer; FOSS NIR Systems Inc, Laurel, MD, USA) and no differences between equivalent spectra were detected [25]. 
The pre-processing procedure (radiometric, geometric, and atmospheric correction) on airborne, satellite, and UAS images introduces uncertainty in the spectra, compromising the comparability of different campaigns and of remote spectra and spectra from soil libraries $[27,28]$. However, a shorter distance between the UAS sensor and soil surface may result in a more robust acquisition of soil spectra, relative to airborne or satellite sensors. A UAS equipped with an incoming sunlight sensor can also provide a reliable at the surface reflectance, in contrast to satellite or airborne sensors, where the reflectance is calculated using atmospheric correction models. These characteristics make UAS-based soil sensing particularly suitable for spatial continuous mapping.

Here, we present a pilot study to investigate the capabilities of a range of hyper- and multi-spectral sensors that can be mounted on UAS for SOC estimation. The main objective was to compare the influence of spectral resolution and range on SOC prediction accuracy when employing UAS-portable sensors in laboratory and outdoor conditions (where we explicitly consider changing illumination and atmospheric conditions and sensor distance). We acquired reflectance from soil samples at close range (from few $\mathrm{cm}$ to 2-3 $\mathrm{m}$ ), in both laboratory and outdoor conditions, using a range of sensors mounted on a tripod. The performance of multivariate calibration models applied to the spectra acquired by two portable hyperspectral sensors (STS-VIS and STS-NIR from Ocean Optics), and two miniature multispectral cameras (Parrot Sequoia and Tetracam Mini-MCA6), was compared to those obtained with a high-end hyper-spectral sensor (ASD Fieldspec 3 FR). Finally, we analysed the transferability of the prediction models between different measurement setups.

\section{Materials and Methods}

The experimental design used in this study is summarized in a flowchart (Figure 1). It includes data collection and pre-processing, a comparison of instrument performances, and an evaluation of model transferability. We further detail the design below.

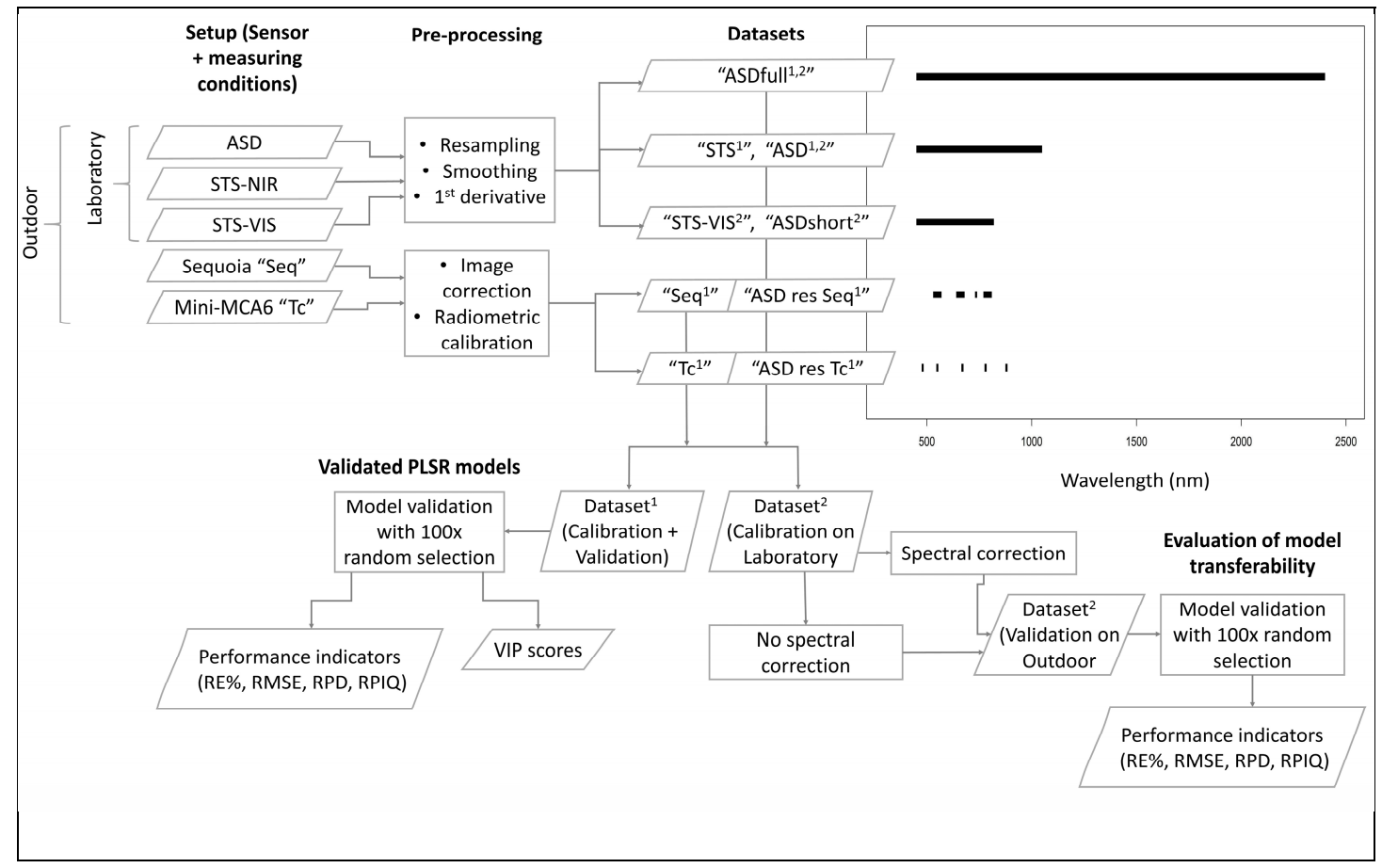

Figure 1. Flowchart of the experimental design.

\subsection{Soil Datasets}

In total, 96 soil samples from one of the Rothamsted long-term field experiments were used. The samples $(0-2 \mathrm{~cm})$ were taken from the Hoosfield Spring Barley Experiment, plots 72, 62, and 42 [19,29]. 
The soil on Hoosfield (Batcombe series; classified as a Chromic Luvisol [30,31]) is a flinty-silty-clay loam overlying clay with flints [32]. The experimental design includes plots that have received different amounts and combinations of mineral fertilizers and organic manures, resulting in plots with very different SOC contents. The plots are ploughed to a depth of $23 \mathrm{~cm}$ each year. Consequently, the whole top-soil $(0-23 \mathrm{~cm})$ layer is regularly mixed and the $C$ content of the plough layer is relatively homogeneous. The SOC content of the 96 samples used in this study ranged between 8.2 and $46.7 \mathrm{~g} \cdot \mathrm{kg}^{-1}\left(\right.$ mean $\left.=16.56 \mathrm{~g} \cdot \mathrm{kg}^{-1}, \mathrm{sd}=10.82 \mathrm{~g} \cdot \mathrm{kg}^{-1}\right)$. Fresh soil samples were oven-dried $(72 \mathrm{~h}$ $\left.60{ }^{\circ} \mathrm{C}\right)$, ground, and sieved ( $<2 \mathrm{~mm}$ with a sieving machine) prior to analysis. The total carbon content for all samples was obtained in a laboratory by dry combustion (using a VarioMAX CN Analyser Elementar $\mathrm{GmbH}$, Germany). The inorganic carbon content of the soil was measured following the method of Sherrod et al. [33]. SOC was obtained by subtracting the inorganic carbon content from the total carbon content. Each sample was distributed on a petri dish (diameter $6.5 \mathrm{~cm}$ ) for spectral data acquisition.

\subsection{Sensor Equipment}

The hyperspectral sensors employed were the STS-VIS and STS-NIR (Ocean Optics Inc., Dunedin, FL, USA). The STS-VIS covers the wavelength range $350-800 \mathrm{~nm}$, while the latter covers the range 650-1100 nm. Both sensors are compact $(40 \times 42 \times 24 \mathrm{~mm})$ and ultra-light $(60 \mathrm{~g})$ and provide light intensity values with an output optical resolution of $1.5 \mathrm{~nm}$, resampled at a $0.45 \mathrm{~nm}$ data output resolution. Each single spectral acquisition with the STS instruments was performed with an integration time of $0.5 \mathrm{~s}$.

The multispectral sensors employed were the Sequoia (Parrot Drones S.a.s., Paris, France) and Mini-MCA6 (Tetracam Inc., Chatsworth, CA, USA). The Sequoia (Seq) measures $59 \times 41 \times 30 \mathrm{~mm}$ and weighs $72 \mathrm{~g}$. It is a camera equipped with five imaging sensors: one for common RGB images and the other four for spectral bands centred at 550,660,735, and $790 \mathrm{~nm}$ wavelengths, with a width of 40,40, 10, and $40 \mathrm{~nm}$ respectively. The field of view is $61.9 \times 48.5 \mathrm{deg}$ and the image resolution is $1280 \times 960$ pixels. The Sequoia works in combination with an incident light sensor that provides an image-level correction factor for changing illumination conditions during image acquisition. The Mini-MCA6 (Tc) measures $134 \times 93 \times 78 \mathrm{~mm}$ and weighs $1080 \mathrm{~g}$. It can be customized with a series of band-pass filters. We selected six lenses to filter six spectral windows, centred at 480, 550, 670, 780, 880, and $1000 \mathrm{~nm}$ wavelengths, with a width of $10 \mathrm{~nm}$. Nevertheless, only the first five windows were used in this experiment (the window at $1000 \mathrm{~nm}$ was malfunctioning). The field of view of the camera is $38.3 \times$ $31.0 \mathrm{deg}$, while the image resolution is $1280 \times 1024$ pixels.

The sensor used as the reference was an ASD Fieldspec 3 FR spectro-radiometer sensor (Analytical Spectral Devices Inc.) that provides light intensity data in the VIS-NIR-SWIR region (350-2500 nm) with an optical resolution of $3 \mathrm{~nm}$ in the $350-1000 \mathrm{~nm}$ region and $10 \mathrm{~nm}$ for the $1000-2500 \mathrm{~nm}$ region, resampled at a $1 \mathrm{~nm}$ data output resolution. Each single spectral acquisition with the ASD instruments was performed with an integration time of $5.4 \mathrm{~s}$.

All sensors and characteristics considered in this study are summarized in Table 1.

Table 1. Spectral resolution of the sensors used in this study.

\begin{tabular}{ccccc}
\hline Instrument & Type & $\begin{array}{c}\text { Wavelength Range } \\
\mathbf{( n m )}\end{array}$ & $\begin{array}{c}\text { Output Resolution } \\
(\mathbf{n m})\end{array}$ & $\begin{array}{c}\text { Spectral Windows } \\
\text { (nm) }\end{array}$ \\
\hline ASD & hyperspectral & $350-2500$ & 1 & $/$ \\
STS-VIS & hyperspectral & $350-800$ & 0.45 & $/$ \\
STS-NIR & hyperspectral & $650-1100$ & 0.45 & $/$ \\
& & $/$ & $/$ & $550 \pm 20,660 \pm 20$ \\
Sequoia & multispectral & & & $735 \pm 5,790 \pm 20$ \\
& & $/$ & $/$ & $480 \pm 5,550 \pm 5$, \\
Mini-MCA6 & multispectral & & & $870 \pm 5,780 \pm 5$, \\
& & & & $880 \pm 5,1000 \pm 5$ \\
\hline
\end{tabular}




\subsection{Spectral Measurements}

Radiometric calibration was performed on all raw data acquired from the hyperspectral and multispectral sensors to obtain reflectance data. For the hyperspectral sensors (ASD and STS), the process involved the spectral measurement of a Spectralon white reference surface. Conversion to reflectance was automatically managed by the acquisition software (RS ${ }^{3}$ software from ASD, OceanView software from OceanOptics). This calibration was repeated every six samples. Radiometric calibration and image correction for the Sequoia were performed by taking a picture of a calibration panel (Parrot Sequoia Calibration Target) and then post-processing the images following the procedure described on the manufacturer's website [34], using the software R [35]. Radiometric calibration and image correction for the Mini-MCA6 were performed by taking a picture of the Sequoia calibration panel and following the procedure described in Aldana-Jague et al. [19], using the software R.

The spectral measurements of the soil samples were carried out both in laboratory and outdoor conditions. Hyperspectral data with ASD, STS-VIS, and STS-NIR were acquired in both setups, while multispectral acquisitions could only be made outdoors:

- Laboratory setup ("Lab" dataset): all samples were scanned once, by the ASD and the STS sensors, using the ASD contact probe, which is equipped with its own light source (100 W halogen reflectorized lamp), and that allows for a spot size of $10 \mathrm{~mm}$ of diameter. Measures were carried out with the probe in contact with the soil sample, in a dark room to minimize sources of disturbance (Figure 2, left).

- Outdoor setup (“Out" dataset): all samples were scanned once, in an open area, to minimize reflection from vertical objects in the surroundings, with stable, clear-sky, natural sunlight conditions for the whole duration of the measurements. In the ASD and STS cases, the sensor head was set at a $10 \mathrm{~cm}$ height above the samples, at the nadir position, providing a measuring spot size of $4.4 \mathrm{~cm}$ of diameter (Figure 2, right). In the cameras cases, the pictures were taken from a low altitude (c. $2 \mathrm{~m}$ ) in the nadir position above the samples, resulting in c. $[0-9]\{1\}-,[0-9]\{1$, pixels/sample.
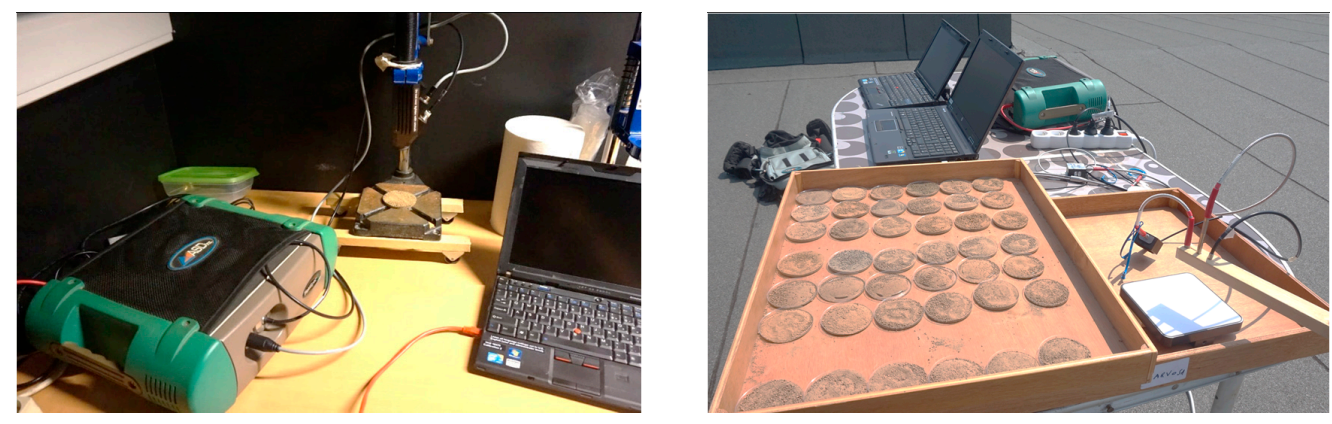

Figure 2. The experiment setup in laboratory (left) and outdoor (right) conditions.

\subsection{Comparison between Measurement Setups}

All STS-VIS and STS-NIR spectra were resampled to match the ASD output resolution of $1 \mathrm{~nm}$. They were then merged in a single continuous spectrum in the VIS-NIR range 450-1050 nm (named "STS" dataset), applying a splice interpolation on the common spectral window to correct for the step between the different sensors. Bandwidths below $450 \mathrm{~nm}$ and beyond $1050 \mathrm{~nm}$ were removed to eliminate areas with excessive signal noise. ASD spectra were both used in their full spectral range ("ASDfull" dataset, in the 450-2400 nm VIS-NIR-SWIR range, after removing the noisy bands) and cut to the same range of the "STS" ("ASD" dataset) to allow for a comparison. For the "ASDfull" spectra, the noisy bands in the water absorption intervals (1350-1450 and 1800-1950 nm) were removed, in accordance with the ranges used by Castaldi et al. [4]. Both "ASD" and "STS" spectra acquired in outdoor conditions ("Out" dataset) were smoothed with a Savitzky-Golay transformation [36] 
using a second-order polynomial fit. Then, to facilitate SOC modelling through Partial Least Squares Regression (PLSR), data transformation with 1st derivative (1D), continuum removal (cr), and standard normal variate (snv) were applied and tested. To evaluate the performance of the cameras (respectively "Seq" and "Tc" datasets for Sequoia and Mini-MCA6 cameras), four sub-datasets were extracted from the laboratory and outdoor "ASD" dataset, by resampling to match the spectral windows of Sequoia and Mini-MCA6 (respectively "ASD res Seq" and "ASD res Tc", for laboratory and outdoor). The data processing was carried out in the software R, using the "prospectr" package [37].

As a preliminary analysis, Pearson's correlation between SOC and wavelengths was calculated on the full spectral range for both "ASD" laboratory and outdoor setups. Two parameters were calculated in four ranges (450-1050, 1051-1999, 2000-2400, and 450-2400 nm): (i) the Root Mean Squared correlation (RMScorr) and (ii) the percentage of bands with a correlation significantly different from $0(p<0.05)$.

PLSR models were then developed for all groups, i.e., combinations of conditions (Lab and Out), instruments, and data transformations, using the R package "pls" [38]. First, the skewness of the SOC distribution of the calibration datasets was reduced by using a logarithmic transformation. For each group, a PLSR model with up to 25 latent variables and "Leave-one-out" cross validation was built, with the aim of selecting the optimal number of latent variables. The best PLSR model within each group was selected based on the number of latent variables (PLSR components) that provided the first local minimum in the relation between the cross-validated RMSE and the number of components. To evaluate the robustness of the models, a validation was then performed, for each group, splitting the data into a calibration and validation dataset $(70 \%$ and $30 \%$, respectively), with random selection, for 100 repetitions. The performance of the models was tested on the validation datasets using the mean of 100 simulations of the following metrics: (i) Relative Error percentage (RE\%), (ii) Root Mean Square Error of prediction (RMSE), (iii) coefficient of determination $\left(R^{2}\right)$, (iv) Ratio of Performance to Deviation (RPD), and (v) Ratio of Performance to Interquartile range (RPIQ) [39]. The significance of the differences between the means of performance indicators, in terms of RMSE, RPD, and RPIQ, was evaluated using a $t$ test for all the comparisons hereby discussed. Furthermore, the importance of the wavelengths relevant for SOC estimation according to the PLSR was identified by the VIP index (Variable Importance for the Projection) [40]. A VIP $>1$ was considered as a criterion for the detection of relevant bands, following Chong \& Jun [41].

\subsection{Model Transferability between Measurement Setups}

The dataset was used to test the stability of the spectral measurements collected by ASD and STS-VIS under different acquisition conditions, namely between the laboratory and outdoors. The tests concerned the STS-VIS measurements between 450 and $820 \mathrm{~nm}$ ("STS-VIS" dataset) and the ASD data at three spectral ranges: 450-2400 nm ("ASDfull" dataset), 450-1100 nm ("ASD" dataset), and 450-820 nm ("ASDshort" dataset).

The dataset was randomly split 100 times in a calibration (75\%) and validation (25\%) dataset for each test. The SOC values and the laboratory spectral data of each calibration dataset were then used to build a PLSR model, which was tested on the validation dataset composed of spectral data acquired in outdoor conditions.

We also validated the PLSR models obtained from both ASD and STS-VIS instruments, both under laboratory and outdoor conditions $(450-820 \mathrm{~nm})$, on data acquired with the other sensor. For example, the calibration dataset derived from the ASD-VIS laboratory spectra was used to validate the STS outdoor dataset.

All the above-mentioned SOC calibration models were also applied before and after the normalization of the spectra using an internal soil standard [42]. For this purpose, one Australian white sand sample (named Lucky bay) was used as a soil standard. This sand was chosen because: (i) the size and shape of the grains are similar to natural soil, (ii) reiterated spectral measurements are stable across the whole spectral region, (iii) spectral features are negligible, and (iv) the sample is stable 
because it consists almost entirely of quartz [43]. The Lucky Bay sand sample was scanned using ASD and STS-VIS spectroradiometers, both under laboratory and outdoor conditions. All the sand spectral data were acquired the same day of the soil measurements and using the same protocol described in the previous section. The sand spectra acquired with ASD and STS-VIS (secondary instruments) were compared with the benchmark spectrum, namely the Lucky Bay spectrum acquired with an ASD spectroradiometer (primary instrument) in the Commonwealth Scientific and Industrial Research Organisation (CSIRO) laboratory.

The soil spectral measurements were corrected with a correction factor based on the following equation:

$$
C_{\lambda}=1-\left(\frac{\rho_{s l, \lambda}-\rho_{b e, \lambda}}{\rho_{s l, \lambda}}\right)
$$

where $\lambda$ is a given wavelength, $\rho_{s l, \lambda}$ is the reflectance of the Lucky Bay sand measured with one of the secondary instruments in laboratory or outdoor conditions, and $\rho_{b e, \lambda}$ is the Lucky Bay sand reflectance acquired at the CSIRO laboratory (benchmark spectrum).

Then, the correction factor $C_{\lambda}$ is applied to the original soil spectra acquired with the secondary instrument, $R_{s o, \lambda}$, obtaining the corrected spectra $R_{s c, \lambda}$ (Equation (2)):

$$
R_{s c, \lambda}=R_{s o, \lambda} \times C_{\lambda}
$$

The average statistic values (RE\%, RMSE, RPD, RPIQ) of the 100 iterations of each test were computed before and after the application of the correction factor based on the Lucky bay sand. The significance of the differences between the means of performance indicators, in terms of RMSE, RPD, and RPIQ, was evaluated using a $t$ test for all the comparisons hereby discussed.

\section{Results}

\subsection{Validated PLSR Models}

The correlation plot (Figure 3) between SOC and spectral wavelengths based on the "ASDfull" laboratory dataset showed strongly correlated bands in the range $500-850 \mathrm{~nm}$, and an average RMScorr of 0.53 for the $450-1050 \mathrm{~nm}$ spectral region. In total, $78 \%$ of wavelengths were significantly correlated to SOC (Table 2). Almost the same result was obtained when taking into account the full spectrum, with an average RMScorr of 0.48 and $77 \%$ of bands significantly correlated; nonetheless, the range between 1000 and $2000 \mathrm{~nm}$ was characterized by overall poorly correlated bands (average RMScorr $=0.32$ ), while only the range between 2000 and $2400 \mathrm{~nm}$ showed good correlation values (average RMScorr $=0.67$, with $93 \%$ of bands significantly correlated). For outdoor conditions, the scores for the 450-1050 nm range were just slightly lower than those obtained under laboratory conditions, with an average RMScorr of $0.49 \%$ and $70 \%$ of wavelengths significantly correlated. On the other hand, the average RMScorr dropped consistently both in the 1050-1999 (RMScorr $=0.16,32 \%$ of wavelengths correlated) and 2000-2400 nm ranges (RMScorr $=0.19,37 \%$ of wavelengths correlated).

Table 2. Root Mean Squared correlation (RMScorr) of the four spectral regions for the "ASDfull" laboratory and outdoor setups.

\begin{tabular}{cccccc}
\hline \multirow{2}{*}{ Setup } & & \multicolumn{4}{c}{ Spectral Range (nm) } \\
\hline \multirow{2}{*}{ Laboratory } & RMScorr & 0.53 & 0.32 & 0.67 & 0.48 \\
& $\% p<0.05$ & 78 & 67 & 93 & 77 \\
Outdoor & RMScorr & 0.49 & 0.16 & 0.19 & 0.28 \\
& $\% p<0.05$ & 70 & 32 & 37 & 47 \\
\hline
\end{tabular}

The performances of PLSR models built from the "ASD" and "ASDfull" data were first compared to evaluate the possibility of modelling SOC content from the VIS-NIR window only (Table 3, Figures 4 
and 5). First derivative transformation provided the best results in comparison to continuum removal and standard normal variate. Therefore, only the first transformation method was used for the comparisons. Differences in terms of RMSE (2.2 and $2.1 \mathrm{~g} \cdot \mathrm{kg}^{-1}$, respectively), RPD (5.3 and 5.4, respectively), and RPIQ (6.2 and 6.9, respectively) were not significant for the laboratory dataset $(p>0.05)$. Under outdoor conditions, however, the use of the full spectral range caused a significant decrease in performances, i.e., the RMSE increased from 2.6 to 3.9, the RPD decreased from 4.2 to 2.9, and the RPIQ decreased from 4.9 to 3.6.

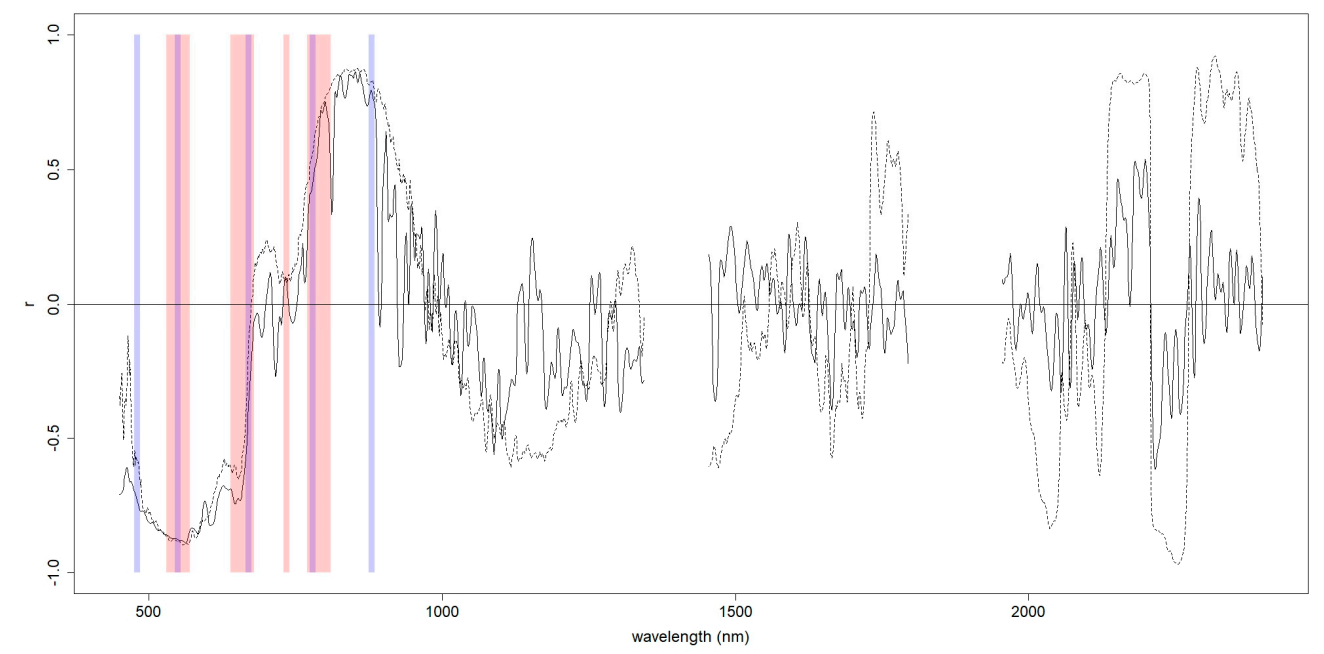

Figure 3. Pearson's correlation plot between SOC and spectral wavelengths for the "ASDfull" laboratory (dashed line) and outdoor (solid line) setups. The spectral windows of the Sequoia (Seq) are highlighted in red and Mini-MCA6 (Tc) in blue.

When comparing the "ASD" and the "STS", the latter performed $~ 30 \%$ worse for all indices in the laboratory setup (RMSE $=2.9 \mathrm{~g} \cdot \mathrm{kg}^{-1}, \mathrm{RPD}=3.9, \mathrm{RPIQ}=4.5$ ) and even less in the field setup (RMSE $=4.2 \mathrm{~g} \cdot \mathrm{kg}^{-1}, \mathrm{RPD}=2.6$ and RPIQ $=3$; Table 3, Figures 4 and 5). For the Sequoia and Mini-MCA6 multispectral cameras, we obtained an RMSE of 2.7 and $3.3 \mathrm{~g} \cdot \mathrm{kg}^{-1}$ and an RPD of 4.2 and 3.5, respectively. These results were comparable to the performances of the "ASD", using the VIS-NIR spectral range only, under outdoor conditions. Furthermore, it should be noted that the cameras outperformed the "STS" when used outdoors. We also compared the performance of the cameras and of the laboratory and outdoor "ASD" data resampled on cameras' spectral windows, to test the effects of size and position of these windows. Laboratory "ASD res Seq" gave an RMSE of $2.4 \mathrm{~g} \cdot \mathrm{kg}^{-1}$ and an RPD of 4.7, and laboratory "ASD res Tc" gave an RMSE of $2.6 \mathrm{~g} \cdot \mathrm{kg}^{-1}$ and RPD of 4.4. The outdoor "ASD" data resampled on the same windows gave results which were not statistically different from the laboratory resampling $(p>0.05)$. The average bias estimated with the RE $\%$ was low for all models (Table 3).

Table 3. RE\%, RMSE ( $\mathrm{g} \cdot \mathrm{kg}^{-1}$ ), RPD, RPIQ, and $\mathrm{R}^{2}$ of the validation PLSR performances (data reported represents the mean value over 100 repetitions) for all the instruments and setups: "ASD", "ASDfull", "STS", "ASD res Seq", "ASD res Tc", "Seq", and "Tc". The number of latent variables (n comp) used in each model is also reported.

\begin{tabular}{|c|c|c|c|c|c|c|c|c|c|c|c|c|}
\hline \multirow[b]{2}{*}{ Dataset } & \multicolumn{8}{|c|}{ Laboratory Setup } & \multicolumn{4}{|c|}{ Outdoor Setup } \\
\hline & $n^{\circ}$ Comp & RE\% & RMSE & RPD & RPIQ & $\mathbf{R}^{2}$ & $n^{\circ}$ Comp & RE\% & RMSE & RPD & RPIQ & $\mathbf{R}^{2}$ \\
\hline "ASD" & 3 & 0.51 & 2.2 & 5.3 & 6.2 & 0.96 & 5 & 0.8 & 2.6 & 4.2 & 4.9 & 0.94 \\
\hline "ASDfull" & 3 & 1 & 2.1 & 5.4 & 6.9 & 0.96 & 7 & 2.7 & 3.9 & 2.9 & 3.6 & 0.89 \\
\hline "STS" & 3 & 2.4 & 2.9 & 3.9 & 4.5 & 0.94 & 6 & 3.1 & 4.2 & 2.6 & 3.0 & 0.85 \\
\hline "ASD res Seq" & 4 & 0.48 & 2.4 & 4.7 & 5.1 & 0.95 & 4 & 0.45 & 2.5 & 4.4 & 5.6 & 0.95 \\
\hline "ASD res Tc" & 5 & 0.17 & 2.6 & 4.4 & 5.3 & 0.95 & 5 & 0.79 & 2.5 & 4.5 & 5.2 & 0.95 \\
\hline "Sequoia" & / & / & / & / & / & / & 4 & 0.82 & 2.7 & 4.2 & 5.1 & 0.94 \\
\hline "Tc" & / & / & / & I & / & / & 5 & 2.2 & 3.3 & 3.5 & 4.5 & 0.93 \\
\hline
\end{tabular}



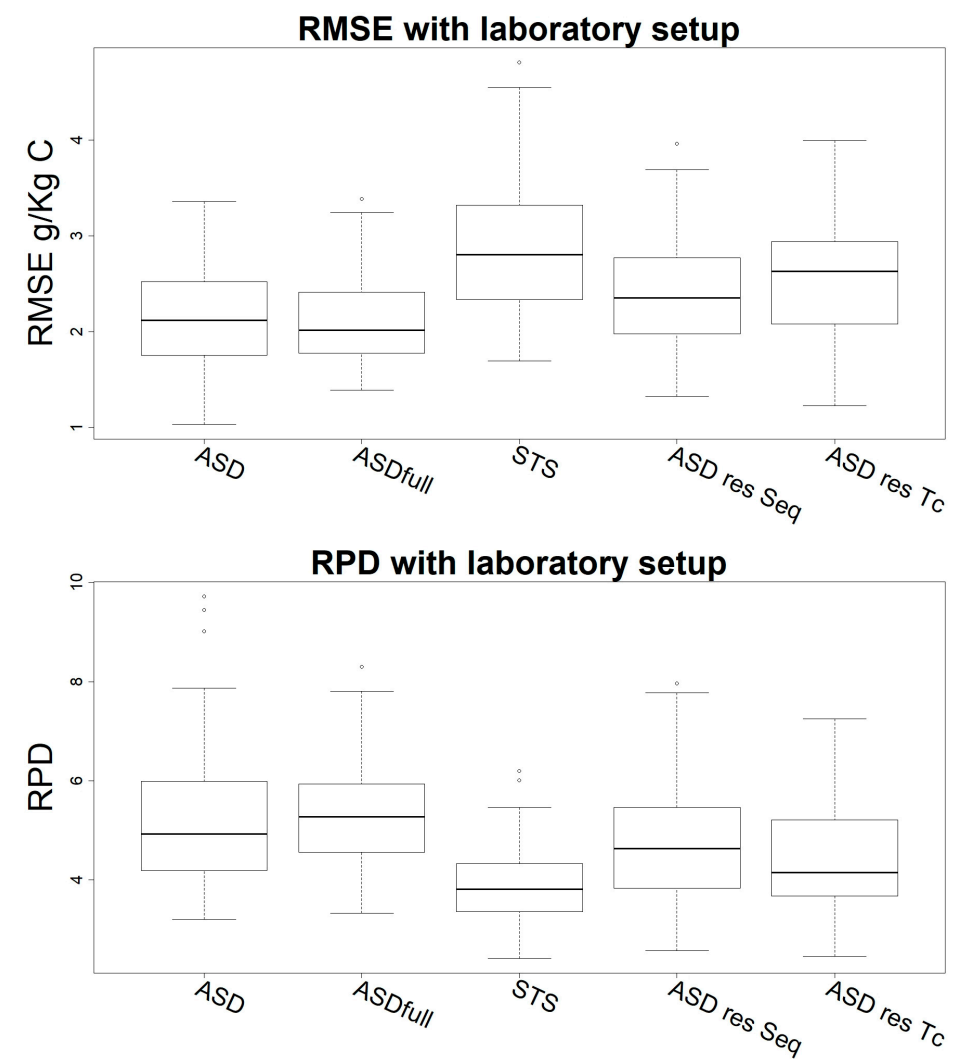

Figure 4. RMSE and RPD from the validation of the models built under laboratory conditions: "ASD", "ASDfull”, "STS", “ASD res Seq", and "ASD res Tc".
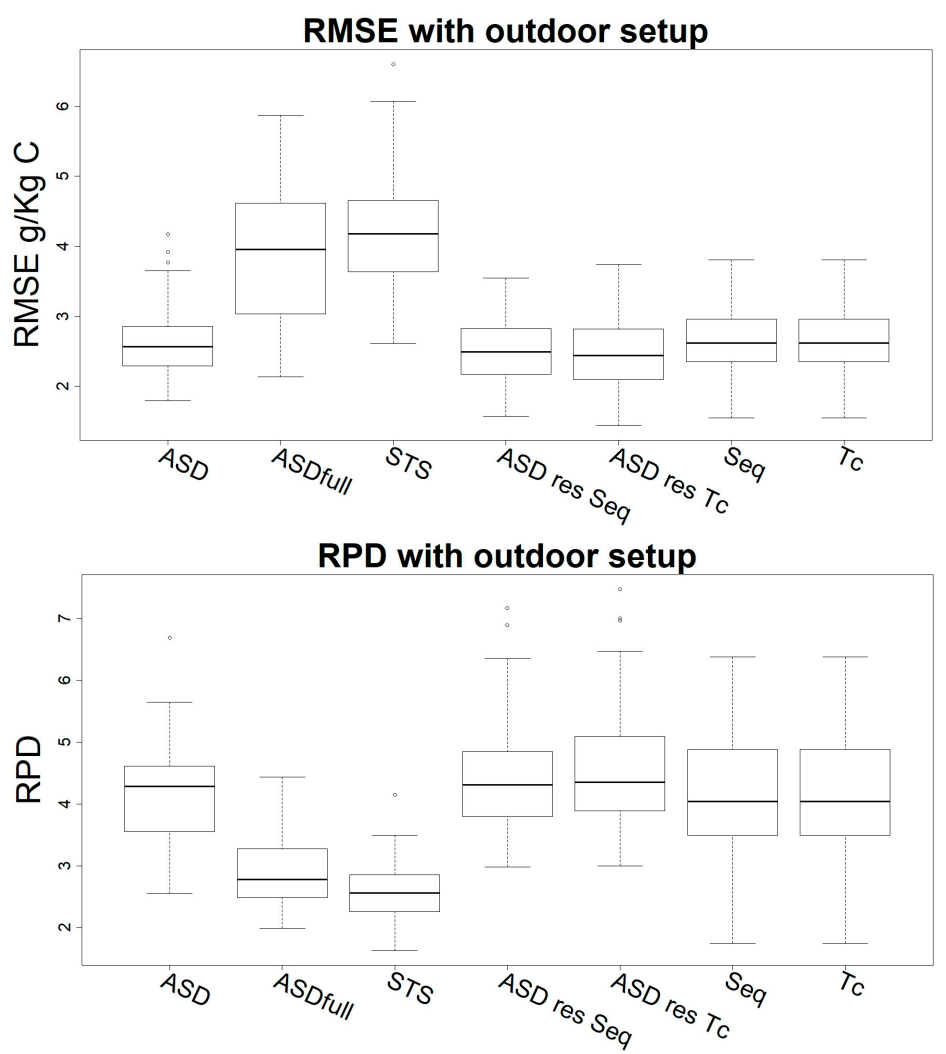

Figure 5. RMSE and RPD from the validation of the models built under outdoor conditions: "ASD", "ASDfull”, "STS", “ASD res Seq", "ASD res Tc", “Seq", and "Tc". 
The plots with the observed versus predicted SOC values from all models used in the comparison of the measuring setups are presented in Figure A1a-1.

The VIP scores calculated for both the "ASD" laboratory and outdoor setups showed a similar trend in the whole VIS-NIR range, highlighting a large single region of interest (VIP > 1) for the PLSR models in the 500-600 $\mathrm{nm}$ range (Figure 6). The models built from the cameras were, on the contrary, exploiting all spectral windows except for the one centered on the $550 \mathrm{~nm}$ region.

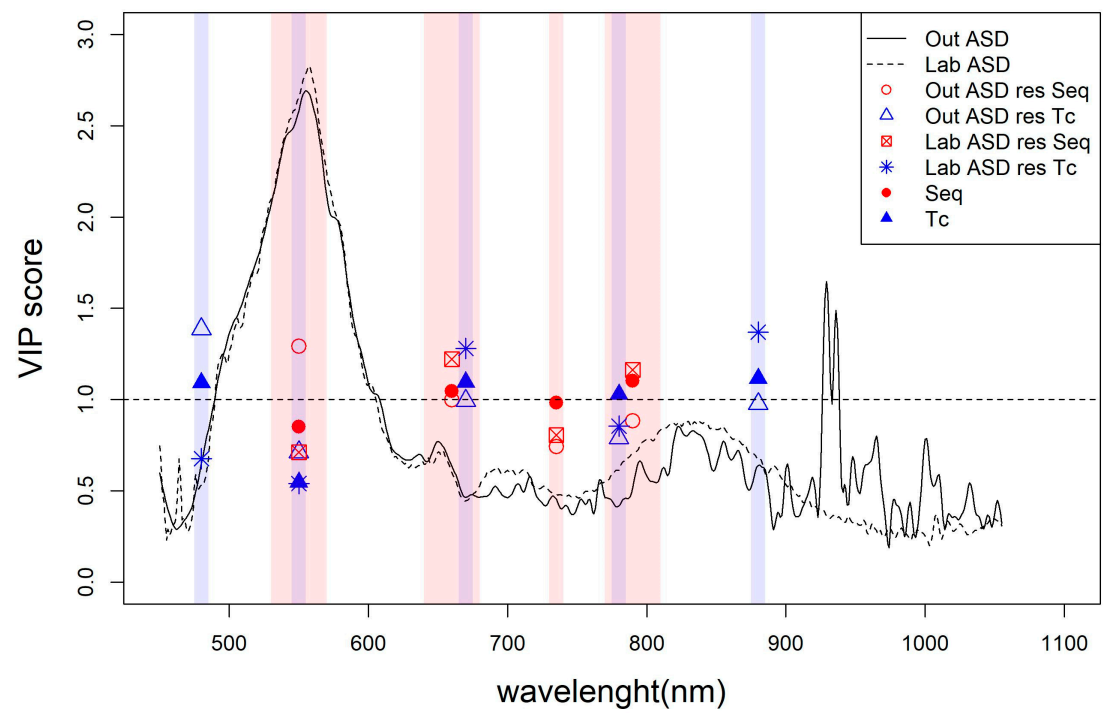

Figure 6. VIP scores in the VIS-NIR range from the PLSR models: laboratory and outdoor "ASD", laboratory and outdoor "ASD res Seq" and "ASD res Tc", and outdoor "Seq" and "Tc".

\subsection{Evaluation of Model Transferability}

The models that were calibrated with the laboratory ASD data, and without applying the correction factor $C_{\lambda}$, were successfully validated with outdoor ASD spectra for all spectral ranges (Table 4). The best estimation accuracies were obtained with a reduced range ("ASDshort" and "ASD"); in these cases, the RPD was higher than 3 and RMSE was $3.1 \mathrm{~g} \cdot \mathrm{kg}^{-1}$ for the $450-1100 \mathrm{~nm}$ range and $3.4 \mathrm{~g} \cdot \mathrm{kg}^{-1}$ for the $450-820 \mathrm{~nm}$ range. The use of the full 450-2400 nm spectrum data ("ASDfull") degraded the estimation accuracy (RMSE $\left.=4.6 \mathrm{~g} \cdot \mathrm{kg}^{-1} ; \mathrm{RPD}=2.5 ; \mathrm{RPIQ}=3.0\right)$. After the application of the correction factor, the statistics did not improve for any of the ASD data, while the use of the $C_{\lambda}$ allowed us to align the "STS-VIS" laboratory and "STS-VIS" outdoor spectra. In fact, the RPD after the correction increased from 1.4 to 2.9 (Table 4). The models calibrated using "ASD" laboratory data were successfully tested on "STS-VIS" outdoor data (RMSE $=4.4 \mathrm{~g} \cdot \mathrm{kg}^{-1} ; \mathrm{RPD}=2.5 ; \mathrm{RPIQ}=2.9$ ), and the correction factor allowed us to slightly improve the accuracy.

Table 4. RMSE ( $\mathrm{g} \cdot \mathrm{kg}^{-1}$ ), RPD, RPIQ, and $\mathrm{R}^{2}$ of PLSR performances of transferred models, both with and without the application of a spectral correction using an internal soil standard.

\begin{tabular}{|c|c|c|c|c|c|c|c|c|c|c|c|}
\hline \multicolumn{2}{|c|}{ Dataset } & \multicolumn{5}{|c|}{ No Spectral Correction } & \multicolumn{5}{|c|}{ Spectral Correction } \\
\hline Calibration & Validation & $\mathrm{RE} \%$ & RMSE & RPD & RPIQ & $\mathbf{R}^{2}$ & $\mathrm{RE} \%$ & RMSE & RPD & RPIQ & $\mathbf{R}^{2}$ \\
\hline Lab "ASDshort" & Out "ASDshort" & -0.4 & 3.4 & 3.2 & 4.0 & 0.9 & 0.6 & 3.4 & 3.2 & 3.8 & 0.9 \\
\hline Lab “ASD” & Out “ASD" & -5.3 & 3.1 & 3.5 & 4.3 & 0.9 & -18.3 & 5.7 & 2.3 & 2.5 & 0.7 \\
\hline Lab "ASDfull" & Out "ASDfull” & -24.4 & 4.6 & 2.5 & 3.0 & 0.8 & 20.9 & 4.7 & 2.4 & 2.6 & 0.8 \\
\hline Lab “STS-VIS" & Out "STS-VIS" & 34.7 & 7.8 & 1.4 & 1.6 & 0.4 & 14.6 & 3.7 & 2.9 & 3.2 & 0.9 \\
\hline Lab "ASDshort" & Out "STS-VIS" & 11.5 & 4.4 & 2.5 & 2.9 & 0.8 & -7.8 & 4.2 & 2.6 & 3.1 & 0.8 \\
\hline
\end{tabular}

\section{Discussion}

The use of spectral sensors that can be mounted on UAS-based platforms for the analysis of soil properties requires optimization. First, UAS payload and battery limitations typically require 
small and very light sensors. Secondly, their detection capabilities have to be optimized, which is related to the spectral features of the target variable and requires a priori knowledge of the spectral characteristics of all sensed objects for successful applications of any quantitative analysis [44].

The spectral features related to SOC are located along many spectral regions, due to the heterogeneity of its components. Some important features were detected in the NIR and SWIR regions $[2-4,45,46]$. These are mainly related to specific chemical bonds between carbon and hydrogen $(\mathrm{C}-\mathrm{H})$ at 1340-1380 nm, the amide nitrogen-hydrogen bond $(\mathrm{N}-\mathrm{H})$, and the bond between Oxygen and Hydrogen in the hydroxyl group, both at 1860-1900 nm. Lignin and cellulose influence the reflectance, respectively, between 1600-1800 $\mathrm{nm}$ and around $2100 \mathrm{~nm}$ [47]. Other features linked to cellulose, lignin, and starch can be found around $2300 \mathrm{~nm}$, close to features related to phenolic, amide, and aliphatic groups [44]. Important correlations between reflectance and organic carbon content were also detected in the VIS region. Although these strong correlation values in the VIS region were mainly reported to be due to the direct relationship between the soil colour and the organic matter abundance $[4,47]$, specific wavelengths and spectral regions were identified. Strong correlations with SOC were found in the VIS region between 550 and $700 \mathrm{~nm}$ [48], between 526 and $587 \mathrm{~nm} \mathrm{[6],} \mathrm{and} \mathrm{in} \mathrm{the} \mathrm{600-800} \mathrm{nm}$ range [49]. Strong correlation between reflectance and SOC was also found within narrower ranges centred at 490 [2], $660 \mathrm{~nm}$ [47,50,51], and $750 \mathrm{~nm}$ [52]. Melendez-Pastor et al. [6] have already pointed out that the cost-effectiveness of field spectro-radiometers for SOC detection could benefit from their focus on the VIS range and our findings are in line with this statement.

Starting from the analysis of laboratory ASD data, we found regions with a strong average correlation in the 500-850 $\mathrm{nm}$ and $2000-2400 \mathrm{~nm}$ ranges, but our PLSR models showed that the differences in performance between VIS-NIR and full spectrum (VIS-NIR-SWIR) datasets are not significant $(p>0.05)$ in terms of SOC prediction accuracy. Since the range between 1050 and $1999 \mathrm{~nm}$ was characterized by overall poorly correlated bands, it is therefore possible that this portion of the spectrum is not informative for SOC and its inclusion in PLSR modelling deteriorates overall performances, at least for the specific soil and SOC range we used in this study. When moving from laboratory to outdoor conditions, the model performances decreased when including the SWIR (Table 3, Figures 4 and 5). Indeed, while the correlation for the VIS-NIR range was just slightly lower than the one observed in the laboratory, they dropped both in the 1050-1999 and 2000-2400 nm ranges. This may be due to the lower signal-to-noise ratio of the ASD under outdoor conditions, especially in the $2000-2400 \mathrm{~nm}$ range (Figure 7).

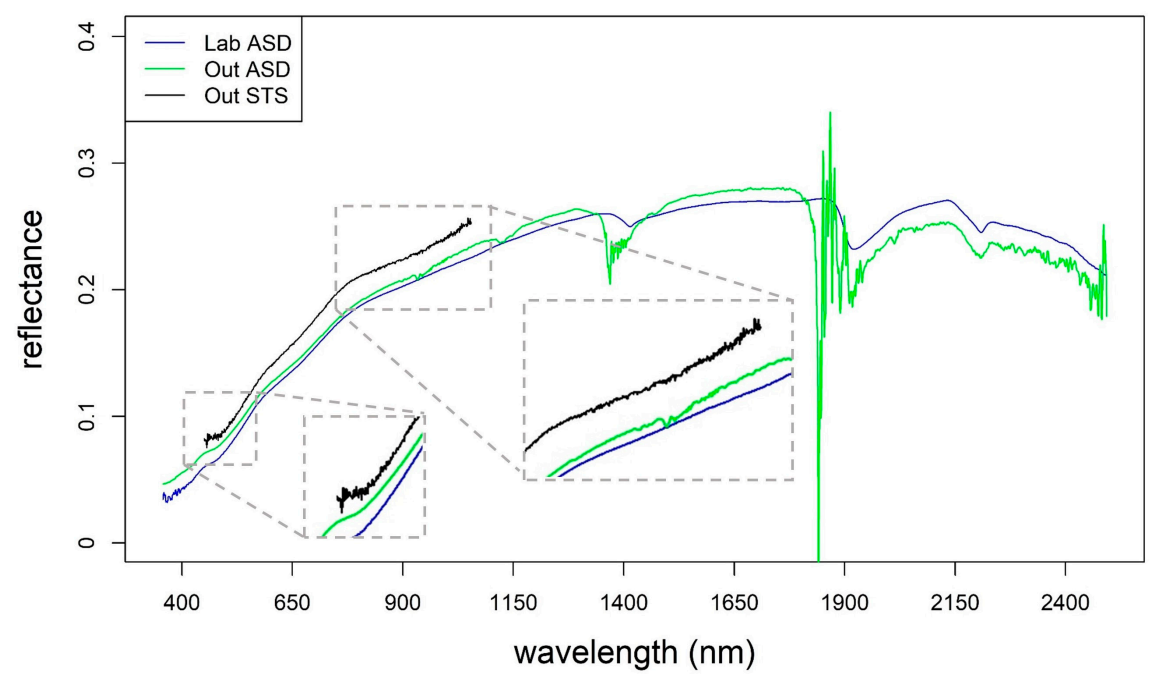

Figure 7. Example of soil sample spectrum as registered by the ASD in laboratory conditions (in blue) and by ASD and STS in outdoor conditions (green and black, respectively). Head and tail of the STS signal are zoomed to highlight the higher noise, as compared to the ASD signals. 
The SOC prediction accuracy obtained with the "STS" dataset was lower than that obtained with the "ASD" data. This was most probably due to the presence of important noise in the wavelengths at the start $(<500 \mathrm{~nm})$ and at the end $(>900 \mathrm{~nm})$ of its spectrum, especially for the outdoor setup (Figure 7, in the zoomed windows). This noise was probably due to the shorter integration time used for data acquisition with the STS instruments ( $0.5 \mathrm{~s})$, to simulate "in-flight" operational conditions, compared to the ASD one (5.4 s).

The Sequoia and Mini-MCA6 cameras yielded good performances, possibly due to the fact that some of their spectral windows, especially those centred at 550,660, and $670 \mathrm{~nm}$, match portions of the spectrum that are strongly correlated to SOC (Figure 3). In particular, the Sequoia-based model yielded results similar to those of the ASD in outdoor conditions. The hyperspectral and multispectral resolutions influenced the VIP values in different ways: on the one hand, hyperspectral data exploited the 500-600 nm range that appears to be a very informative region, probably for its slope, (e.g., Bartholomeus et al. [47]). On the other hand, multispectral data mainly exploited the other windows up to $880 \mathrm{~nm}$ (Figure 6). The narrow bands used in the Sequoia camera, centred at 660 and $790 \mathrm{~nm}$, cover a spectral range more correlated to SOC than the narrow bands available for our Mini-MCA6 in the same regions (Figure 3). This is supported by the observation that the PLSR performances obtained using the outdoor ASD spectra resampled on the cameras' windows showed better results when using the Sequoia narrow bands than the Mini-MCA6 ones (Table 3).

The results from the comparison of the validation sets provided some important information on the contribution of different spectral regions and resolutions, and on the influence of setup conditions on SOC prediction accuracy. Nevertheless, it should be noted that the outdoor setup was not fully representing real field conditions. Although the outdoor measurements were made under conditions similar to those in the field (natural sunlight, moist air, and sensor distance), the effects of soil roughness and soil moisture were eliminated in this study. Furthermore, the sensors were not mounted on a drone, but were installed on a tripod, to facilitate the scanning of a range of soil samples with different sensors. In addition, our tests were performed on soils collected from several plots with different SOC contents within a single field experiment and may not fully represent typical ranges of SOC that can be found in real-life conditions. Although new research should be carried out to prove the effectiveness of mapping SOC using UAS-based data under real flight conditions [19], the information obtained here can be used to understand the potential and limitations of different sensor setups.

Another key problem related to SOC mapping is the extrapolation of these empirical models to areas that differ from the ones where the calibration was obtained. This is often very difficult, costly, or just impossible. Consequently, the collection of a specific dataset for each investigated area is necessary in order to obtain an accurate quantitative estimation of the target soil property. Nevertheless, the collection of a calibration dataset requires an extensive sampling and laboratory analysis. However, many large soil spectral libraries covering local to global scales $[26,53]$ already exist. Once the issue of the alignment between datasets is solved, they could be exploited to predict soil properties in another dataset. The alignment between laboratory spectra acquired using two different protocols or instruments is a common practice in soil spectroscopy [54]. This goal can be achieved by applying a spectral transfer function, which is obtained by scanning some soil samples using both instruments. An alternative practice is the alignment by means of an internal soil standard [42]. These techniques could be very attractive to apply predictive models, calibrated with laboratory spectra, to proximal and remote sensing data. However, their use is mainly hampered by the uncertainty of the atmospheric correction, which affects the spectral responses from remote sensing data [27]. For this reason, only a few studies have dealt with the transfer between laboratory and remote spectra $[27,28]$. Obviously, reducing the distance between the sensor and soil could reduce the issues related to atmospheric correction and UAS-borne sensors could be used for this purpose; however, we are not aware of studies dealing with the alignment between laboratory and UAS spectral data. This is probably due to the large differences between the spectral resolution of laboratory instruments and UAS borne cameras/sensors. Although many light hyperspectral sensors are currently available, 
their performances for soil properties prediction are still poorly quantified. In this study, we tried to validate laboratory PLSR models for outdoor spectra with and without the alignment by an internal soil standard. Our tests highlighted a good correspondence between the laboratory ASD and outdoor ASD spectra without spectral correction. The worst result with ASD data was obtained using the "ASDfull" range (450-2400 nm), and this is due to the important noise in the SWIR region of the outdoor measurements that increases the difference with the laboratory "ASDfull" (Figure 7). It should be noted that this was also visible in the correlations between reflectance and SOC (Figure 3). The main differences between outdoor ASD and laboratory ASD spectra are in the NIR-SWIR region, while in the VIS, the two spectra have very similar trends and values (Figure 7). The STS-VIS sensor showed a larger difference between laboratory and outdoor spectra, relative to the ASD. In fact, the performance statistics of the validation after the spectral correction consistently increased. However, the "STS-VIS" performance is still lower than the one obtained with the ASD for the same spectral range ("ASDshort" $450-820 \mathrm{~nm}$ ). These results show that exploiting a predictive model calibrated with laboratory data to outdoor spectra obtained by the same instruments is feasible. However, it should be noted that for the "STS-VIS", a spectral correction was necessary. The differences between ASD and STS-VIS were mainly due to the high noise in the STS-VIS spectra, especially for the outdoor measurements (Figure 7). In addition, in this case, a satisfactory correspondence between the outputs of the two instruments can be observed ( $\mathrm{RPD}=2.5)$, and no significant improvement, in terms of prediction accuracy, was observed when applying $C_{\lambda}$.

\section{Conclusions}

The UAS-compatible hyperspectral sensors and multi-spectral cameras operating in the VIS-NIR spectral range that were tested in this study are able to provide data with a sufficient quality for developing SOC prediction models in outdoor conditions. SOC prediction modelling based on the narrow bands of the two multispectral cameras (Parrot Sequoia and Tetracam Mini-MCA6) provided better performances than those obtained with the STS hyperspectral sensors. Furthermore, the model built on the Sequoia camera reached the same performance (RMSE $=2.7, \mathrm{RPD}=4.2$ ) as the reference ASD instrument in outdoor conditions (RMSE $=2.6, \mathrm{RPD}=4.2$ ). VIP scores of our PLSR models showed that: i) the spectral region between 500 and $600 \mathrm{~nm}$ contains most information for hyperspectral SOC modelling, and ii) the VIS-NIR range up to about $900 \mathrm{~nm}$ is exploited when using multispectral narrow bands. Validation results indicate that the VIS-NIR range alone may be sufficient for SOC prediction, at least for the conditions encountered in this study. Consequently, the implementation of small-form VIS-NIR portable sensors in UAS systems could be a viable strategy to improve the effectiveness of SOC assessments. Moreover, we showed that it is possible to exploit predictive models calibrated with hyperspectral laboratory data on outdoor spectra obtained by the same portable instruments, applying a correction factor based on an internal soil standard. Together, this shows that UAS-based multispectral and hyperspectral sensors have the potential to estimate soil organic carbon on bare soils with an acceptable accuracy and at a much higher spatial and temporal resolution than existing methodologies.

Author Contributions: Conceptualization, F.C., B.v.W., and K.V.O.; Data curation, G.C., E.A.-J., and A.M.; Funding acquisition, K.V.O.; Investigation, G.C. and F.C.; Software, E.A.-J.; Supervision, B.v.W., A.M., and K.V.O.; Writing original draft, G.C. and F.C.

Funding: The Rothamsted Long-term Experiments National Capability (LTE-NC) is supported by the UK BBSRC (Biotechnology and Biological Sciences Research Council, BBS/E/C/000J0300) and the Lawes Agricultural Trust. This study was supported in part by funding from the ExpeER (Experimentation in Ecosystem Research) project under the European Union's 7th Framework Program (No. 262060). The study was also supported by the RAPAS research project SR/00/328 of the BELSPO-STEREO research programme for earth observation.

Acknowledgments: Giacomo Crucil is an ASP of the Fonds de la Recherche Scientifique (FNRS). We thank the Lawes Agricultural Trust and Rothamsted Research for access to information and data from the electronic Rothamsted Archive (e-RA) website and database (http:/ / www.era.rothamsted.ac.uk/Hoosfield).

Conflicts of Interest: The authors declare no conflict of interest. 


\section{Appendix A}

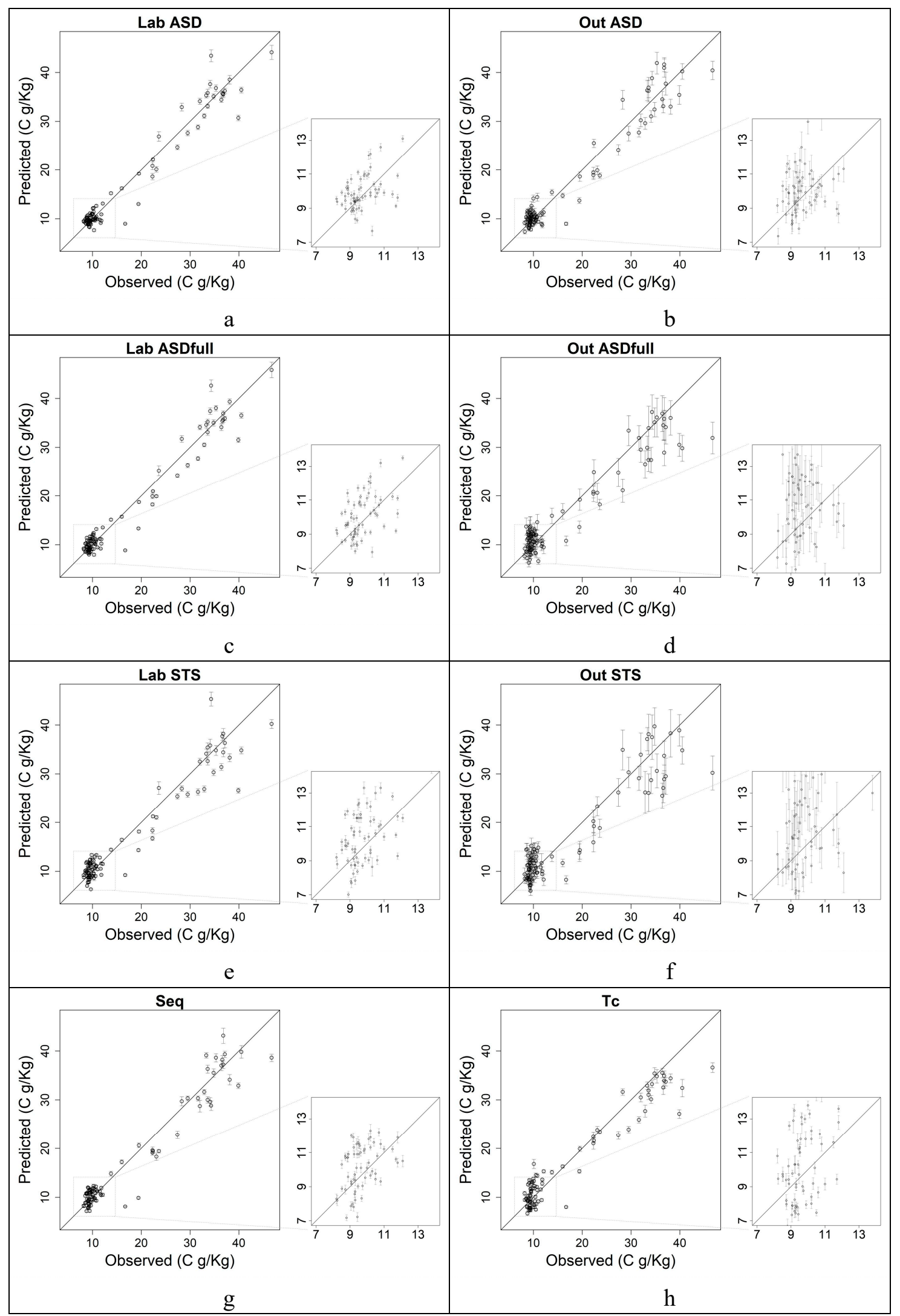

Figure A1. Cont. 


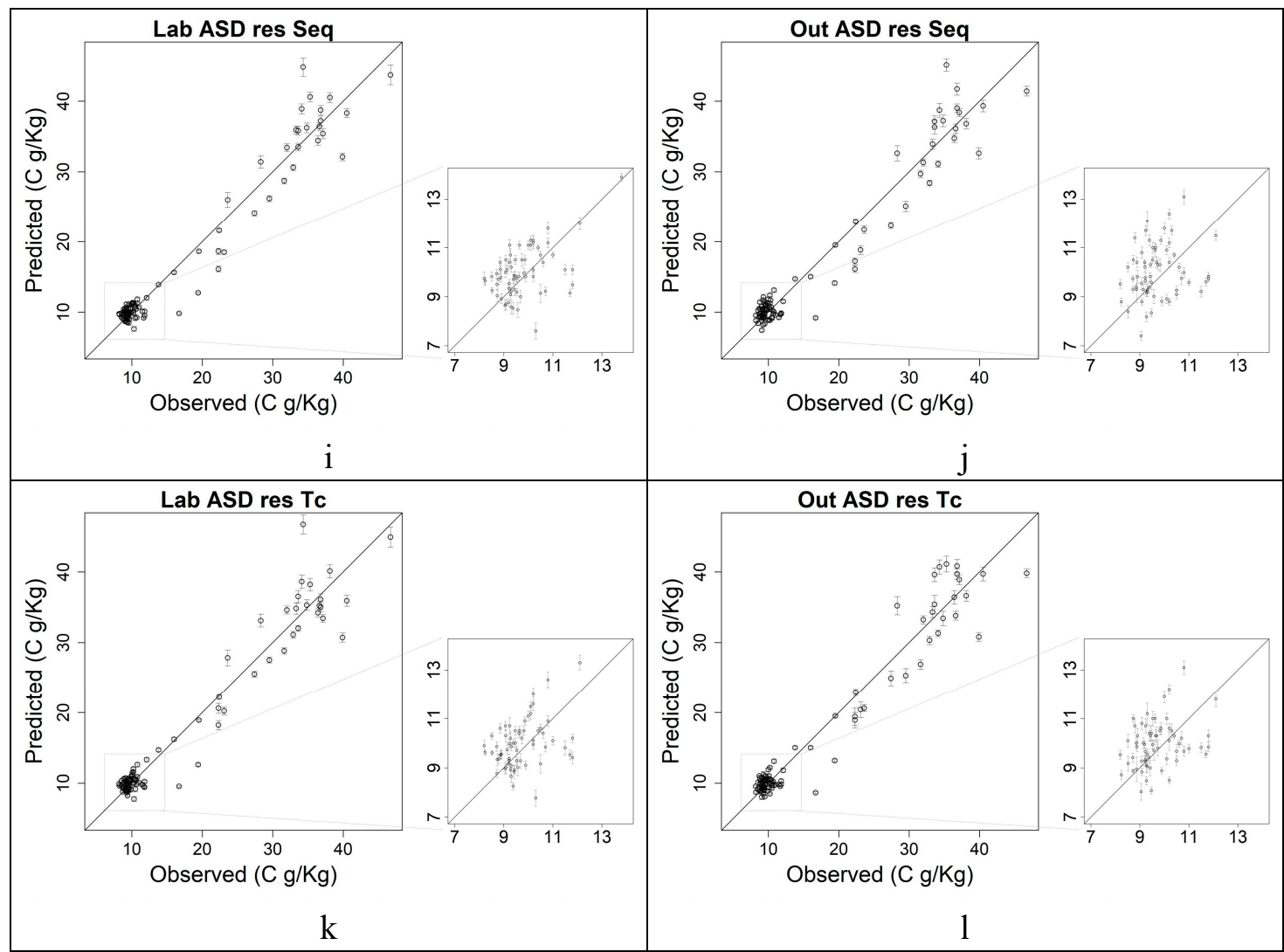

Figure A1. Plots of observed versus predicted SOC values from the models used in the comparison of the measuring setups. Vertical error bars represent the standard deviation obtained from the validation process through 100x random selection.

\section{References}

1. Nocita, M.; Stevens, A.; van Wesemael, B.; Aitkenhead, M.; Bachmann, M.; Barthès, B.; Ben Dor, E.; Brown, D.J.; Clairotte, M.; Csorba, A.; et al. Soil Spectroscopy: An Alternative to Wet Chemistry for Soil Monitoring. Adv. Agron. 2015, 132, 139-159. [CrossRef]

2. Mouazen, A.M.; Maleki, M.R.; De Baerdemaeker, J.; Ramon, H. On-line measurement of some selected soil properties using a VIS-NIR sensor. Soil Tillage Res. 2007, 93, 13-27. [CrossRef]

3. Stenberg, B.; Viscarra Rossel, R.A.; Mouazen, A.M.; Wetterlind, J. Visible and Near Infrared Spectroscopy in Soil Science. In Advances in Agronomy; Academic Press: Cambridge, MA, USA, 2010; Volume 107, pp. 163-215.

4. Castaldi, F.; Palombo, A.; Santini, F.; Pascucci, S.; Pignatti, S.; Casa, R. Evaluation of the potential of the current and forthcoming multispectral and hyperspectral imagers to estimate soil texture and organic carbon. Remote Sens. Environ. 2016, 179, 54-65. [CrossRef]

5. Nawar, S.; Mouazen, A.M. Predictive performance of mobile vis-near infrared spectroscopy for key soil properties at different geographical scales by using spiking and data mining techniques. Catena 2017, 151, 118-129. [CrossRef]

6. Melendez-Pastor, I.; Navarro-Pedreño, J.; Gómez, I.; Koch, M. Identifying optimal spectral bands to assess soil properties with VNIR radiometry in semi-arid soils. Geoderma 2008, 147, 126-132. [CrossRef]

7. Stevens, A.; Udelhoven, T.; Denis, A.; Tychon, B.; Lioy, R.; Hoffmann, L.; van Wesemael, B. Measuring soil organic carbon in croplands at regional scale using airborne imaging spectroscopy. Geoderma 2010, 158, 32-45. [CrossRef]

8. Castaldi, F.; Casa, R.; Castrignanò, A.; Pascucci, S.; Palombo, A.; Pignatti, S. Estimation of soil properties at the field scale from satellite data: A comparison between spatial and non-spatial techniques. Eur. J. Soil Sci. 2014, 65, 842-851. [CrossRef] 
9. Castaldi, F.; Hueni, A.; Chabrillat, S.; Ward, K.; Buttafuoco, G.; Bomans, B.; Vreys, K.; Brell, M.; Wesemael, B. Van ISPRS Journal of Photogrammetry and Remote Sensing Evaluating the capability of the Sentinel 2 data for soil organic carbon prediction in croplands. ISPRS J. Photogramm. Remote Sens. 2019, 147, 267-282. [CrossRef]

10. Kruse, F.A.; Boardman, J.W.; Huntington, J.F. Comparison of airborne hyperspectral data and EO-1 Hyperion for mineral mapping. IEEE Trans. Geosci. Remote Sens. 2003, 41, 1388-1400. [CrossRef]

11. Casa, R.; Castaldi, F.; Pascucci, S.; Basso, B.; Pignatti, S. Geophysical and Hyperspectral Data Fusion Techniques for In-Field Estimation of Soil Properties. Vadose Zone J. 2013, 12, vzj2012.0201. [CrossRef]

12. Guanter, L.; Kaufmann, H.; Segl, K.; Foerster, S.; Rogass, C.; Chabrillat, S.; Kuester, T.; Hollstein, A.; Rossner, G.; Chlebek, C.; et al. The EnMAP Spaceborne Imaging Spectroscopy Mission for Earth Observation. Remote Sens. 2015, 7, 8830-8857. [CrossRef]

13. Pignatti, S.; Acito, N.; Amato, U.; Casa, R.; Castaldi, F.; Coluzzi, R.; De Bonis, R.; Diani, M.; Imbrenda, V.; Laneve, G.; et al. Environmental products overview of the Italian hyperspectral prisma mission: The SAP4PRISMA project. In Proceedings of the 2015 IEEE International Geoscience and Remote Sensing Symposium (IGARSS), Milan, Italy, 26-31 July 2015; pp. 3997-4000.

14. Itten, I.K.; Dell'Endice, F.; Hueni, A.; Kneubühler, M.; Schläpfer, D.; Odermatt, D.; Seidel, F.; Huber, S.; Schopfer, J.; Kellenberger, T.; et al. APEX-the Hyperspectral ESA Airborne Prism Experiment. Sensors 2008, 8, 6235-6259. [CrossRef]

15. Colomina, I.; Molina, P. Unmanned aerial systems for photogrammetry and remote sensing: A review. ISPRS J. Photogramm. Remote Sens. 2014, 92, 79-97. [CrossRef]

16. Eltner, A.; Schneider, D. Analysis of Different Methods for 3D Reconstruction of Natural Surfaces from Parallel-Axes UAV Images. Photogramm. Rec. 2015, 30, 279-299. [CrossRef]

17. Soriano-Disla, J.M.; Janik, L.J.; Allen, D.J.; McLaughlin, M.J. Evaluation of the performance of portable visible-infrared instruments for the prediction of soil properties. Biosyst. Eng. 2017, 161, 24-36. [CrossRef]

18. Matese, A.; Toscano, P.; Di Gennaro, S.; Genesio, L.; Vaccari, F.; Primicerio, J.; Belli, C.; Zaldei, A.; Bianconi, R.; Gioli, B. Intercomparison of UAV, Aircraft and Satellite Remote Sensing Platforms for Precision Viticulture. Remote Sens. 2015, 7, 2971-2990. [CrossRef]

19. Aldana-Jague, E.; Heckrath, G.; Macdonald, A.; van Wesemael, B.; Van Oost, K. UAS-based soil carbon mapping using VIS-NIR (480-1000 nm) multi-spectral imaging: Potential and limitations. Geoderma 2016, 275, 55-66. [CrossRef]

20. Ben-Dor, E. Soil spectracl imaging, moving from proximal sensing to spatial quantitative domain. ISPRS Ann. Photogramm. Remote Sens. Spat. Inf. Sci. 2012, 1, 67-70.

21. Zhang, C.; Kovacs, J.M. The application of small unmanned aerial systems for precision agriculture: A review. Precis. Agric. 2012, 13, 693-712. [CrossRef]

22. Nebiker, S.; Lack, N.; Abächerli, M.; Läderach, S. Light-Weight Multispectral Uav Sensors and Their Capabilities for Predicting Grain Yield and Detecting Plant Diseases. ISPRS-Int. Arch. Photogramm. Remote Sens. Spat. Inf. Sci. 2016, XLI-B1, 963-970. [CrossRef]

23. Gilliot, J.-M.; Vaudour, E.; Michelin, J.; Houot, S. Estimation des teneurs en carbone organique des sols agricoles par télédetection par drone. Revue Française de Photogrammétrie et de Télédétection 2017, 213-214, 105-115.

24. Mulder, V.L.; de Bruin, S.; Schaepman, M.E.; Mayr, T.R. The use of remote sensing in soil and terrain mapping-A review. Geoderma 2011, 162, 1-19. [CrossRef]

25. Tóth, G.; Jones, A.; Montanarella, L. The LUCAS topsoil database and derived information on the regional variability of cropland topsoil properties in the European Union. Environ. Monit. Assess. 2013, 185, 7409-7425. [CrossRef] [PubMed]

26. Rossel, R.A.V.; Behrens, T.; Ben-Dor, E.; Brown, D.J.; Demattê, J.A.M.; Shepherd, K.D.; Shi, Z.; Stenberg, B.; Stevens, A.; Adamchuk, V.; et al. A global spectral library to characterize the world's soil. Earth-Sci. Rev. 2016, 155, 198-230. [CrossRef]

27. Castaldi, F.; Chabrillat, S.; Jones, A.; Vreys, K.; Bomans, B.; van Wesemael, B. Soil Organic Carbon Estimation in Croplands by Hyperspectral Remote APEX Data Using the LUCAS Topsoil Database. Remote Sens. 2018, 10, 153. [CrossRef]

28. Nouri, M.; Gomez, C.; Gorretta, N.; Roger, J.M. Clay content mapping from airborne hyperspectral Vis-NIR data by transferring a laboratory regression model. Geoderma 2017, 298, 54-66. [CrossRef] 
29. Rothamsted Research. Guide to the Classical and Other Long-Term Experiments, Datasets and Sample Archive; Lawes Agriculture Trust Co. Ltd.: Harpenden, UK, 2006; pp. 8-18.

30. IUSS Working Group WRB. World Reference Base for Soil Resources 2014, update 2015 International soil classification system for naming soils and creating legends for soil maps. In World Soil Resources Reports No. 106; FAO: Rome, Italy, 2015.

31. Bull, I.D.; Van Bergen, P.F.; Poulton, P.R.; Evershed, R.P. Organic geochemical studies of soils from the Rothamsted Classical Experiments-II, soils from the Hoosfield Spring Barley Experiment treated with different quantities of manure. Org. Geochem. 1998, 28, 11-26. [CrossRef]

32. Glendining, M.J.; Poulton, P.R.; Powlson, D.S.; Jenkinson, D.S. Fate of 15 N-labelled fertilizer applied to spring barley grown on soils of contrasting nutrient status. Plant Soil 1997, 195, 83-98. [CrossRef]

33. Sherrod, L.A.; Dunn, G.; Peterson, G.A.; Kolberg, R.L. Inorganic carbon analysis by modified pressure-calcimeter method. Soil Sci. Soc. Am. J. 2002, 66, 299-305. [CrossRef]

34. Micasens Support. Available online: https://support.micasense.com (accessed on 4 Octorber 2018).

35. R Core Team. R: A Language and Environment for Statistical Computing; R Foundation for Statistical Computing: Vienna, Austria, 2017. Available online: https:/ /www.R-project.org/ (accessed on 4 Octorber 2018).

36. Savitzky, A.; Golay, M.J.E. Smoothing and Differentiation of Data by Simplified Least Squares Procedures. Anal. Chem. 1964, 36, 1627-1639. [CrossRef]

37. Stevens, A.; Ramirez-Lopez, L. An Introduction to the Prospectr Package. R Package Vignette R Package Version 0.1.3. 2013. Available online: ftp://200.236.31.2/CRAN/web/packages/prospectr/vignettes/ prospectr-intro.pdf (accessed on 20 March 2019).

38. Bjørn-Helge, B.-H.; Wehrens, R. The pls Package Principal Component and Partial Least Squares Regression in R. J. Stat. Softw. 2007, 18, 1-23.

39. Bellon-Maurel, V.; Fernandez-Ahumada, E.; Palagos, B.; Roger, J.-M.; McBratney, A. Critical review of chemometric indicators commonly used for assessing the quality of the prediction of soil attributes by NIR spectroscopy. TrAC Trends Anal. Chem. 2010, 29, 1073-1081. [CrossRef]

40. Wold, S.; Sjostrom, M.; Eriksson, L. PLS-regression, a basic tool of chemometrics. Chemom. Intell. Lab. Syst. 2001, 58, 109-130. [CrossRef]

41. Chong, I.-G.; Jun, C.-H. Performance of some variable selection methods when multicollinearity is present. Chemom. Intell. Lab. Syst. 2005, 78, 103-112. [CrossRef]

42. Kopačková, V.; Ben-Dor, E. Normalizing reflectance from different spectrometers and protocols with an internal soil standard. Int. J. Remote Sens. 2016, 37, 1276-1290. [CrossRef]

43. Pimstein, A.; Notesco, G.; Ben-Dor, E. Performance of Three Identical Spectrometers in Retrieving Soil Reflectance under Laboratory Conditions This article has supplemental material available online. Soil Sci. Soc. Am. J. 2011, 75, 746-759. [CrossRef]

44. Ben Dor, E. The Reflectance Spectra of Organic Matter in the Visible Near-Infrared and Short Wave Infrared Region (400-2500 nm) during a Controlled Decomposition Process. Remote Sens. Environ. 1997, 61, 1-15. [CrossRef]

45. Viscarra Rossel, R.A.; Walvoort, D.J.J.; McBratney, A.B.; Janik, L.J.; Skjemstad, J.O. Visible, near infrared, mid infrared or combined diffuse reflectance spectroscopy for simultaneous assessment of various soil properties. Geoderma 2006, 131, 59-75. [CrossRef]

46. Grunwald, S. Multi-criteria characterization of recent digital soil mapping and modeling approaches. Geoderma 2009, 152, 195-207. [CrossRef]

47. Bartholomeus, H.M.; Schaepman, M.E.; Kooistra, L.; Stevens, A.; Hoogmoed, W.B.; Spaargaren, O.S.P. Spectral reflectance based indices for soil organic carbon quantification. Geoderma 2008, 145, 28-36. [CrossRef]

48. Galvao, L.S.; Vitorello, I. Role of organic matter in obliterating the effects of iron on spectral reflectance and colour of Brazilian tropical soils. Int. J. Remote Sens. 1998, 19, 1969-1979. [CrossRef]

49. Conforti, M.; Buttafuoco, G.; Leone, A.P.; Aucelli, P.P.C.; Robustelli, G.; Scarciglia, F. Studying the relationship between water-induced soil erosion and soil organic matter using Vis-NIR spectroscopy and geomorphological analysis: A case study in southern Italy. Catena 2013, 110, 44-58. [CrossRef]

50. Nocita, M. The Contribution of Diffuse Reflectance Spectroscopy to Soil Organic Carbon Analysis: From Laboratory to Airborne Spectroscopy. Ph.D. Thesis, Université Catholique de Louvain, Ottignies-Louvain-laNeuve, Belgium, 2014. 
51. Stevens, A.; Nocita, M.; Toth, G.; Montanarella, L.; van Wesemael, B. Prediction of Soil Organic Carbon at the European Scale by Visible and Near InfraRed Reflectance Spectroscopy. PLoS ONE 2013, 8, e66409. [CrossRef] [PubMed]

52. Ge, Y.; Morgan, C.L.S.; Grunwald, S.; Brown, D.J.; Sarkhot, D.V. Comparison of soil reflectance spectra and calibration models obtained using multiple spectrometers. Geoderma 2011, 161, 202-211. [CrossRef]

53. Panagos, P.; Hiederer, R.; Van Liedekerke, M.; Bampa, F. Estimating soil organic carbon in Europe based on data collected through an European network. Ecol. Indic. 2013, 24, 439-450. [CrossRef]

54. Fearn, T. Standardisation and Calibration Transfer for near Infrared Instruments: A Review. J. Near Infrared Spectrosc. 2001, 9, 229-244. [CrossRef]

(C) 2019 by the authors. Licensee MDPI, Basel, Switzerland. This article is an open access article distributed under the terms and conditions of the Creative Commons Attribution (CC BY) license (http://creativecommons.org/licenses/by/4.0/). 